\title{
Conserved Cytoplasmic Tyrosine Residues of the $\gamma$ Subunit are Required for a Phagocytic Signal Mediated by Fc $\gamma$ RIIIA
}

\author{
Jong-Gu Park, Richard K. Murray, Paul Chien, Christine Darby, and Alan D. Schreiber \\ Department of Medicine, University of Pennsylvania School of Medicine, Philadelphia, Pennsylvania 19104
}

\begin{abstract}
Fc receptors for immunoglobulins are found on many cells and are important in host defense. We transfected FcrRIIIA, present on macrophages and natural killer (NK) cells, into COS-1 cells to study its role in phagocytosis and calcium mobilization in the absence of other Fc $\gamma$ receptors. Human FcrRIIIA- $\alpha$ (CD16) was cotransfected with its associated chains, either Fe $\gamma$ RIIIA $\gamma$ or $\zeta$. Both $\gamma$ and $\zeta$ were observed to induce a phagocytic signal, but $\gamma$ was at least sixfold more effective than $\zeta$. Conservative substitution by phenylalanine of either one of the two cytoplasmic tyrosine residues in the $\gamma$ chain resulted in markedly diminished phagocytosis and calcium mobilization. Tyrphostin 23, an inhibitor of tyrosine kinases, reversibly inhibited phagocytosis. Further, in vitro kinase assays with the wild type and mutant $\gamma$ chains demonstrated that the wild type $\gamma$ chain, but not the mutant $\gamma$ chains, is phosphorylated. These results suggest that the cytoplasmic tyrosine residues and tyrosine phosphorylation are required for Fc $\gamma$ RIIIA to mediate two signal transduction events: phagocytosis and calcium mobilization. (J. Clin. Invest. 1993. 92:2073-2079.) Key words: Fc receptors - phagocytosis - signal transduction - tyrosine phosphorylation • calcium mobilization
\end{abstract}

\section{Introduction}

One important function of $\mathrm{Fc} \gamma$ receptors in host defense is the ingestion or phagocytosis of IgG sensitized cells. There are three classes of human $\mathrm{Fc} \gamma$ receptors, Fc $\gamma \mathrm{RI}, \mathrm{Fc} \gamma \mathrm{RII}$, and Fc $\gamma$ RIII, which are distinguished by their structure, binding affinity, and cellular distribution (1). All $\mathrm{Fc} \gamma$ receptor genes have been mapped to the long arm (q23-24) of chromosome 1 (1) and exhibit highly conserved extracellular domains, but their divergent cytoplasmic structures may have functional implications in signal transduction (2-5).

Address correspondence to Dr. Jong-Gu Park, Department of Medicine, 7 Silverstein Building, University of Pennsylvania School of Medicine, 3400 Spruce Street, Philadelphia, PA 19104.

Received for publication 25 September 1992 and in revised form 24 May 1993.

1. Abbreviations used in this paper: ADCC, antibody-dependent cellular cytotoxicity; E, immunoglobulin E; EA, immunoglobulin EA; MFI, mean fluorescence intensity; NK, natural killer; PI, phagocytic index.

J. Clin. Invest.

(C) The American Society for Clinical Investigation, Inc.

0021-9738/93/10/2073/07 \$2.00

Volume 92, October 1993, 2073-2079
Fc $\gamma$ RIIIA appears to mediate phagocytosis in macrophages and antibody-dependent cellular cytotoxicity (ADCC) ${ }^{1}$ in natural killer (NK) cells $(6,7)$. Fc $\gamma$ RIIIA is a multichain complex of a single $\alpha$ subunit containing IgG binding domains and a disulfide linked homo- or heterodimer of $\gamma$ and $\zeta$ subunits, forming different isoforms by the subunits $(5,8)$. The $\gamma$ chain, initially identified as a dimeric subunit in the tetrameric FceRI complex, is associated with FcrRIIIA in macrophages and NK cells $(8)$. The $\zeta$ chain is associated with the TCR complex in T-cells (9) and the Fc $\gamma$ RIIIA complex in NK cells (10). $\gamma$ and $\zeta$ homo- or heterodimers are essential for surface expression of the $\alpha$ subunits of Fc $\epsilon$ RI and Fc $\gamma$ RIIIA $(8,11)$ and may contribute to signal transduction through a conserved motif containing tyrosine residues in the cytoplasmic tail $(12,13,14)$. The $\gamma$ chain tyrosine(s) is rapidly and reversibly phosphorylated upon crosslinking of FceRI (15).

Definition of the biological functions of each $\mathrm{Fc} \gamma$ receptor has been hindered by the expression of multiple $\mathrm{Fc} \gamma$ receptor family members in most hematopoietic cells and cell lines. $\mathrm{Re}$ cently, COS-1 cells and 3T3 cells, which lack endogenous Fcr receptor, were observed to phagocytose IgG-sensitized cells (EA) when transfected with Fc $\gamma$ receptor $\operatorname{cDNAs}(3,14,16)$. We used COS-1 cells to investigate the capacity of the Fc $\gamma$ RIIIA isoforms to transmit a phagocytic signal. Since Fc $\gamma$ RIIIA- $\gamma \gamma$ appears to be a more efficient signal transducer for phagocytosis, we examined the role of the conserved tyrosine residues of the $\gamma$ chain both in phagocytosis and in calcium mobilization. In addition, in vitro phosphorylation of the tyrosine residues of the $\gamma$ chain was studied and found to be correlated with phagocytic capacity.

\section{Methods}

Plasmid construction and introduction of point mutations. The pSVL eucaryotic expression vector (Pharmacia LKB, Piscataway, NJ) was employed for expression of Fc $\gamma$ RIIIA in COS- 1 cells. COS- 1 cells express the SV40 large T antigen, which efficiently activates the SV40 promoter in pSVL (17). huFc $\gamma$ RIIIA $\alpha$ cDNA (kindly provided by Dr. Bice Perussia, Jefferson College of Medicine, Philadelphia, PA) was cloned into the XbaI and BamHI cloning sites of pSVL. Similarly, mouse Fc $\gamma$ RIIIA $\gamma$ cDNA (kindly provided by Dr. Jean-Pierre Kinet, National Institutes of Health, Bethesda, MD) was cloned into XhoI and BamHI cloning sites. TCR/Fc $\gamma$ RIIIA $\zeta$ (kindly provided by Dr. Richard D. Klausner, National Institutes of Health, Bethesda, MD) was cloned into the XbaI and BamHI cloning sites of pSVL. Conservative replacement of cytoplasmic tyrosines of the $\gamma$ chain by phenylalanine was achieved using the two-step overlap-extension PCR (18). Double tyrosine substitution mutants were constructed sequentially by the substitution of the $\mathrm{NH}_{2}$-terminal tyrosine residue after the substitution of the $\mathrm{COOH}$-terminal tyrosine residue. Six clones from each mutant were isolated and subjected to DNA sequencing. Two clones from 
each tyrosine substitution were randomly selected for further studies from several clones with correct DNA sequences.

Transient transfection. Fc $\gamma$ RIIIA isoforms, Fc $\gamma$ RIIIA- $\gamma \gamma$ and Fc $\gamma$ RIIIA- $\zeta \zeta$, were generated by cotransfection of COS- 1 cells with cDNA of $\gamma$ or $\zeta$ as well as cDNA of $\alpha$. Transfections of cDNAs were carried out with a modified DEAE-Dextran method. Briefly, 300,000 COS- 1 cells were seeded on $35-\mathrm{mm}$ well plates $24 \mathrm{~h}$ before transfection. Plates of 70 to $80 \%$ confluency were washed twice and incubated for 30 min with DME (Gibco BRL, Grand Island, NY) before transfection. 4 $\mu \mathrm{g}$ of plasmid DNA $(0.5 \mu \mathrm{g} / \mu \mathrm{l})$ was slowly added to $1 \mathrm{ml}$ of a transfection buffer containing Nu medium (DME with $10 \%$ NuSerum [Collaborative Biomedical, Two Oak Park, Bedford, MA]), $1 \mathrm{mg} / \mathrm{ml}$ of DEAE Dextran, and $100 \mu \mathrm{M}$ chloroquine. The transfection buffer containing DNA was added to COS- 1 cells with incubation for $4 \mathrm{~h}$ at $37^{\circ} \mathrm{C}$. Cells were then shocked with $10 \%$ DMSO in PBS for 2 min, washed twice with DME, and grown in NuSerum-supplemented DME. Cells were studied $48 \mathrm{~h}$ after transfection.

Immunofluorescence staining and flow cytofluorimetry. Transfected cells were harvested with staining buffer (calcium and magnesium-free PBS containing $0.02 \%$ sodium azide and $0.1 \%$ BSA) using transfer pipettes. Cells were centrifuged, resuspended in $60 \mu \mathrm{l}$ of staining buffer, and incubated with either the anti-Fc $\gamma$ RIII mAb, 3G8 (19), or an isotype control for $30 \mathrm{~min}$ at $4^{\circ} \mathrm{C}$. Cells were washed and stained with fluorescein-conjugated goat anti-mouse IgG (Tago Inc. Burlingame, CA). The stained cells were examined using a FACS ${ }^{\circledR}$ tar flowcytometer (Becton Dickinson Co., Mountain View, CA).

Binding and phagocytosis of IgG-sensitized red blood cells $(E A)$. Sterile sheep red blood cells $\left(10^{9}\right.$ cells $\left./ \mathrm{ml}\right)$ in calcium and magnesiumfree PBS were sensitized by incubation with an equal volume of a subagglutinating titer of rabbit anti-sheep RBC antibody (Cappel Laboratories, Cochranville, PA). The IgG-sensitized RBCs (EA) were washed twice with PBS and resuspended to a final concentration of $10^{9}$ cells/ $\mathrm{ml}$ for overlaying on transfected COS- 1 cells. Cells were examined for rosetting ( $>10 \mathrm{EA}$ per COS- 1 cell) and phagocytosis as described previously (3). For the analysis of phagocytosis, COS-1 cells bound with EA (after three washings) were subjected to a brief hypotonic shock (35 s) with hypotonic PBS to remove surface bound EA. The cells were then stained with Wright-Giemsa staining solutions, and phagocytosis (ingested EA) was determined by light microscopy. Results obtained were analyzed by Student's $t$ test.

In vitro kinase assay. Transfected cells $\left(2 \times 10^{7}\right.$ cells $)$ were washed once with PBS and incubated sequentially on ice with $5 \mu \mathrm{g} / \mathrm{ml}$ each of anti-Fc $\gamma$ RIII $\mathrm{mAb}$ and goat anti-mouse IgG for $10 \mathrm{~min}$. Cells were incubated at room temperature for $3 \mathrm{~min}$ and washed once with PBS before adding $1.5 \mathrm{ml}$ of lysis buffer ( $150 \mathrm{mM} \mathrm{NaCl}, 25 \mathrm{mM}$ Hepes, $\mathrm{pH}$ 7.4 , and $1 \%$ polyoxyethylene 10 oleyl ether [BRIJ-96; Sigma Chemical Co., St. Louis, MO]) containing phosphatase and protease inhibitors. Inhibitors of phosphatases and proteases $(1 \mathrm{mM}$ EGTA, $1 \mathrm{mM} \mathrm{Na}$ orthovanadate, $1 \mathrm{mM}$ PMSF, $10 \mu \mathrm{g} / \mathrm{ml}$ aprotinin, $50 \mu \mathrm{g} / \mathrm{ml}$ leupeptin, and $100 \mu \mathrm{g} / \mathrm{ml}$ soybean trypsin inhibitor) were added fresh to lysis buffer. After $15 \mathrm{~min}$ of lysis on ice, cell lysates were centrifuged for 30 $\min$ at $4^{\circ} \mathrm{C}$ to clarify. The Fc $\gamma$ RIIIA- $\gamma$ chain was immunoprecipitated with anti-human $\gamma$ antiserum (kindly provided by Dr. Jean-Pierre Kinet) and Protein A-sepharose CL4B (Sigma Chemical Co.) in lysis buffer. Pellets were washed three times in lysis buffer and once in low salt buffer ( $100 \mathrm{mM} \mathrm{NaCl}, 25 \mathrm{mM}$ Hepes, $\mathrm{pH} 7.4$, and $5 \mathrm{mM} \mathrm{MnCl}{ }_{2}$ ). Pellets were incubated $\left(20^{\circ} \mathrm{C}, 10 \mathrm{~min}\right)$ with $30 \mu \mathrm{l}$ of a mixture containing $25 \mathrm{mM}$ Hepes, pH 7.4, $5 \mathrm{mM} \mathrm{MnCl}, 5 \mathrm{mM} p$-nitrophenyl-phosphate, $1 \mu \mathrm{M}$ cold ATP (Boehringer Mannheim, Biochemicals, Indianapolis, IN), and $5 \mu \mathrm{Ci} \gamma-\left[{ }^{32} \mathrm{P}\right] \mathrm{ATP}(6,000 \mathrm{Ci}$ or $222 \mathrm{TBq} / \mathrm{mmol}$; Dupont NEN, Boston, MA). Reactions were stopped by adding reducing SDS-PAGE sample buffer and labeled proteins were separated on a $12.5 \%$ reducing SDS-PAGE gel. The gel was fixed in methanol/acetic acid, treated with $1 \mathrm{~N} \mathrm{KOH}\left(2 \mathrm{~h}\right.$ at $\left.55^{\circ} \mathrm{C}\right)$ to remove phosphoserine and phosphothreonine, dried, and autoradiogramed for $4 \mathrm{~d}$.

$\left[\mathrm{Ca}^{2+}\right]$ i mobilization. COS-1 cells plated on glass coverslips were incubated with $2 \mu \mathrm{M}$ Fura-2/AM (Calbiochem-Novabiochem Corp., San Diego, CA) for $30 \mathrm{~min}$, washed twice, and the coverslips then transferred to a Leidem cell chamber (Medical Systems Corp., Greenvale, NY) for multiple single-cell measurements of $\left[\mathrm{Ca}^{2+}\right]$ i. Fc $\gamma$ RIIIA receptors were crosslinked either with biotinylated anti-Fc $\gamma$ RIII followed by the addition of streptavidin or with anti-Fc $\gamma$ RIII mAb 3G8 whole IgG. As a positive control, $10 \mu \mathrm{M}$ epinephrine was added to crosslink epinephrine receptors expressed on COS cells (20). Calcium imaging was performed using a $40 \times$ fluorescence objective on a Diaphot microscope (Nikon Inc., Melville, NY) with the image-1 AT quantitative fluorescence system (Universal Imaging, West Chester, PA). Images were acquired at either 340- or 380-nm excitation (emission $=510 \mathrm{~nm}$ ). $340 / 380$ ratio images were calculated on a pixel by pixel basis and the average $340 / 380$ ratio within each cell determined at each time point. $340 / 380$ ratios were converted to $\left[\mathrm{Ca}^{2+}\right] \mathrm{i}$, based on solution calibration using free Fura-2 acid (21).

\section{Results}

Phagocytosis mediated by Fc $\gamma$ RIIIA $\alpha$ and associated $\gamma$ and $\zeta$ chains. To clearly define the functions ascribed to the individual isoforms of Fc $\gamma$ RIIIA, wild type Fc $\gamma$ RIIIA $\gamma$ and/or $\zeta$ cDNAs were cotransfected with the $\alpha$ chain cDNA into COS- 1 cells to examine their ability to induce phagocytosis of EA (sensitized RBCs). Surface expression of Fc $\gamma$ RIIIA was determined by flow cytometry and was equally efficient in cotransfection with either $\gamma$ or $\zeta$ (Table I). The mean fluorescence intensity (MFI) for cotransfected cells stained with antiFc $\gamma$ RIII mAb increased by 15 -fold compared to cells stained with an IgG isotype control or compared to sham-transfected cells stained with anti-Fc $\gamma$ RIII mAb (Table I). The transfectants were examined for their ability to bind and phagocytose IgG sensitized RBCs (EA). Approximately $50 \%$ of COS-1 transfectants avidly bound EA ( Table I). Microscopic examination of COS-1 cells transfected with wild type $\gamma$ consistently showed the ingestion of EA by $20 \pm 5 \%$ of the cells examined ( $P$ $<0.02$ ). Thus, phagocytosis of EA was detected in approximately $40 \%$ of COS- 1 cell transfectants that bound EA. In contrast, cotransfectants containing the $\zeta$ chain revealed $3.8 \%$ of cells with ingested EA ( $P<0.02$; Table I). Moreover, in $\zeta$-containing cells that demonstrated phagocytosis the average number of ingested EA per cell was reduced to less than one-half that observed with $\gamma$. COS- 1 cells transfected with all three

Table I. Fcy RIIIA Expression and Phagocytosis by COS-1 Cells Transfected with FcrRIIIA ( $\gamma$ and/or $\zeta$ )

\begin{tabular}{lcccc}
\hline Fc $\gamma$ RIIIA & MFI $^{*}$ & PI $^{\ddagger}$ & Phagocytosis & Rosetting \\
\hline \multicolumn{4}{c}{ \% Cells +} \\
Sham & 15 & 0 & 0 & 0 \\
$\alpha+\gamma$ & 254 & $129 \pm 21.0$ & $20 \pm 5.0$ & $48 \pm 3.0$ \\
$\alpha+\zeta$ & 220 & $19 \pm 3.2$ & $3.8 \pm 0.7$ & $50 \pm 1.7$ \\
$\alpha+\zeta+\gamma$ & 205 & $77 \pm 5.0$ & $16 \pm 3.2$ & $46 \pm 2.0$ \\
\hline
\end{tabular}

Transfection efficiency was determined by flow cytometry. The MFI is shown for one of three separate experiments with similar results. At least three separate experiments were performed for each clone. For each experiment, 1,500 cells were counted at five randomly selected sites. Internalized RBCs were microscopically scored $(\times 1,000)$. Results are expressed as the mean \pm SEM for phagocytosis and binding (rosetting) of EA. Sham represents COS-1 cells transfected with Fc $\gamma$ RIIIA $\alpha$ and pSVL vector without a $\gamma$ insert. ${ }^{*}$ MFI per Results. ${ }^{\ddagger}$ Phagocytic index (PI) is the number of RBCs internalized per 100 COS- 1 cells (3). 
cDNAs, $\alpha, \gamma$, and $\zeta$, revealed $16 \%$ cells with ingested EA, showing consistent levels of phagocytosis ( Table I). In contrast, neither sham transfectants with EA nor transfectants with E (nonsensitized RBC) exhibited any binding or phagocytosis.

Two cytoplasmic tyrosines of the $\gamma$ chain are required for phagocytosis. It has been suggested that the conserved tyrosine containing cytoplasmic motif found in several IgG superfamily receptors is important for receptor mediated signal transduction $(4,12)$ (Fig. 1). To study the effect of the two conserved $\gamma$ chain tyrosines on Fc $\gamma$ RIIIA mediated phagocytosis, the $\mathrm{N}$ proximal (clones M1A and M1B) or C-proximal (clones M2A and M2B) tyrosines were individually replaced by phenylalanine. For mutants with double tyrosine substitutions, both tyrosines were replaced by phenylalanine (DMA and DMB) (Fig. 1).

MFI measured by flow cytofluorimetry and percent positive cells with rosetting demonstrated similar surface expression of the receptor complexes in all transfectants bearing wild type and mutant $\gamma$ chains (Table II). These comparable levels of expression indicate that tyrosine residues in the cytoplasmic tail of the $\gamma$ chain are not necessary for formation of the Fc $\gamma$ RIIIA receptor complex required for surface expression. The binding of EA by $\gamma$ mutant transfectants was comparable to that observed with wild type $\gamma$. However, M1 $\gamma$ mutants showed substantially reduced phagocytic activity $(\leq 1 \%$ of transfectants with ingested EA and minimal ingested EA per phagocytosing cell $)(P<0.02)$; M2 and DM $\gamma$ mutants demonstrated essentially no phagocytosis ( 1 among 5,000 cells examined) (Table II, Fig. 2). These results demonstrate that both $\gamma$ chain tyrosines are essential for efficient transduction of a phagocytic signal by Fc $\gamma$ RIIIA.

Inhibition of phagocytosis by tyrphostin 23. To investigate if phagocytosis requires phosphorylation of tyrosine residues, COS- 1 cells cotransfected with Fc $\gamma$ RIIIA- $\alpha$ and wild type $\gamma$

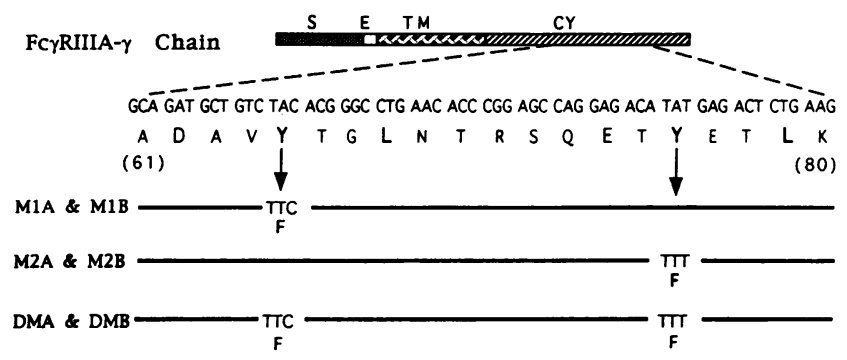

Figure 1. Schematic representation of mouse cDNA of Fc $\gamma$ RIIIA $\gamma$ wild type and mutants. Shown above the schematic diagram of the $\gamma$ chain are signal sequence $(S)$, external peptides $(E)$, transmembrane domain $(T M)$, and cytoplasmic domain $(C Y)$. The expanded area shows an area of the nucleotide sequence of the $\gamma$ chain containing the conserved motif. The conserved amino acids of the gene family of the $\gamma$ and $\zeta$ chain genes are denoted by the boldface letters. The N-proximal tyrosine encoded by the TAC codon of the nucleotides 235-237 (amino acid 65; reference 36 ) was conservatively replaced with phenylalanine encoded by TTC (clones M1A and M1B). Similarly, the C-proximal tyrosine encoded by TAT (268-270; amino acid 76) was replaced with phenylalanine encoded by TTT (clones M2A and M2B). For the double tyrosine-substitution mutants, both the $\mathrm{N}$ - and $\mathrm{C}$-proximal tyrosines were replaced with phenylalanine (clones DMA and DMB). Solid lines of the mutants represent identical sequences to that of the wild type $\gamma$ cDNA. Abbreviations for the amino acids are follows: A, Ala; D, Asp; E, Glu; G, Gly; K, Lys; L, Leu; N, Asn; Q, Gly; R, Arg; S, Ser; T, Thr; V, Val; Y, Tyr.
Table II. FcrRIIIA Expression and Phagocytosis by COS-1 Cells Transfected with FC RIIIA $\alpha$ and $\gamma$ (wild type or mutants)

\begin{tabular}{lcccc}
\hline \multicolumn{1}{c}{ Fc $\gamma$ RIIIA } & MFI & PI & Phagocytosis & Rosetting \\
\hline \multicolumn{4}{c}{} & \multicolumn{4}{c}{$\%$ Cells +} \\
Sham & 15 & 0 & 0 & 0 \\
$\alpha+\gamma$ (WT) & 254 & $129 \pm 21.0$ & $20 \pm 5.0$ & $49 \pm 3.0$ \\
$\alpha+\gamma$ (M1A) & 259 & $0.3 \pm 0.2$ & $0.2 \pm 0.1$ & $49 \pm 2.5$ \\
$\alpha+\gamma$ (M1B) & 303 & $1.0 \pm 1.0$ & $1.0 \pm 1.0$ & $50 \pm 1.5$ \\
$\alpha+\gamma$ (M2A) & 232 & $\leq 0.04$ & $\leq 0.02$ & $49 \pm 1.5$ \\
$\alpha+\gamma$ (M2B) & 256 & $\leq 0.02$ & $\leq 0.02$ & $48 \pm 3.0$ \\
$\alpha+\gamma$ (DMA) & 222 & $\leq 0.02$ & $\leq 0.02$ & $48 \pm 2.5$ \\
$\alpha+\gamma$ (DMB) & 328 & $\leq 0.02$ & $\leq 0.02$ & $49 \pm 2.0$ \\
\hline
\end{tabular}

See Table I for legend. M1A and M1B are two separate mutants with $\mathrm{N}$-proximal tyrosine substitution. M2A and M2B are mutants with C-proximal tyrosine substitution. DMA and DMB are mutants with both $\mathrm{N}$ - and $\mathrm{C}$-proximal tyrosine substitution.

were incubated with increasing concentrations of tyrphostin 23 (tyr 23), an inhibitor of tyrosine kinases (22). Tyr 23 decreased phagocytosis in a dose-dependent manner, with $50 \%$ inhibition at $25 \mu \mathrm{M}$ and complete inhibition at $200-400 \mu \mathrm{M}(P$ $<0.01$ ) (Table III). In contrast, tyr 23 did not affect the binding of EA. Inhibition of phagocytosis was not associated with reduction in viability, since transfectants pretreated with tyr 23 $(400 \mu \mathrm{M})$ after washing had phagocytic activity partially (3-h wash, Table III) or completely (overnight wash, data not shown) restored. This suggests that phagocytosis mediated by Fc $\gamma$ RIIIA requires phosphorylation of tyrosine residues of the $\gamma$ chain and/or other molecules involved in signal transduction.

Tyrosine residues of the $\gamma$ subunit are phosphorylated in vitro. The fact that the two conserved tyrosine residues of the $\gamma$ subunit are important for phagocytosis, and that tyrosine phosphorylation is required for phagocytic signal transduction, suggests that the tyrosine residues of the $\gamma$ chain are phosphorylated. This possibility was examined by in vitro kinase assays using COS-1 transfectants. Results shown in Fig. 3 demonstrated that the tyrosine residues of the wild type $\gamma$ chains were phosphorylated in vitro. In contrast, the mutant $\gamma$ chain transfectants and the sham transfectants showed no detectable phosphorylation. Since the single tyrosine substitution mutants (M1A and M2A) did not exhibit phosphorylation on the remaining tyrosine residues, it is likely that phosphorylation of either one of the two tyrosine residues requires the other tyrosine residue to be intact (Fig. 3). These phosphorylation data correlate well with the ability of the $\gamma$ chain to induce a phagocytic signal, as substitution of either one of the tyrosine residues largely eliminates phagocytosis.

The in vitro kinase assay also demonstrated a distinct band of $\sim 40 \mathrm{kD}$, which was present in all lanes except for the sham transfectants. This band may represent an associated phosphoprotein coprecipitating with $\gamma$.

Cytoplasmic tyrosines of $\gamma$ are required for mobilization of $\mathrm{Ca}^{2+}$. We have previously observed that COS-1 cells cotransfected with the Fc $\gamma$ RIIIA $\alpha$ and $\gamma$ cDNAs mobilize intracellular calcium upon receptor crosslinking (14). To examine whether the $\gamma$ chain tyrosines are required for calcium mobilization, the calcium response following Fc $\gamma$ RIIIA crosslinking 

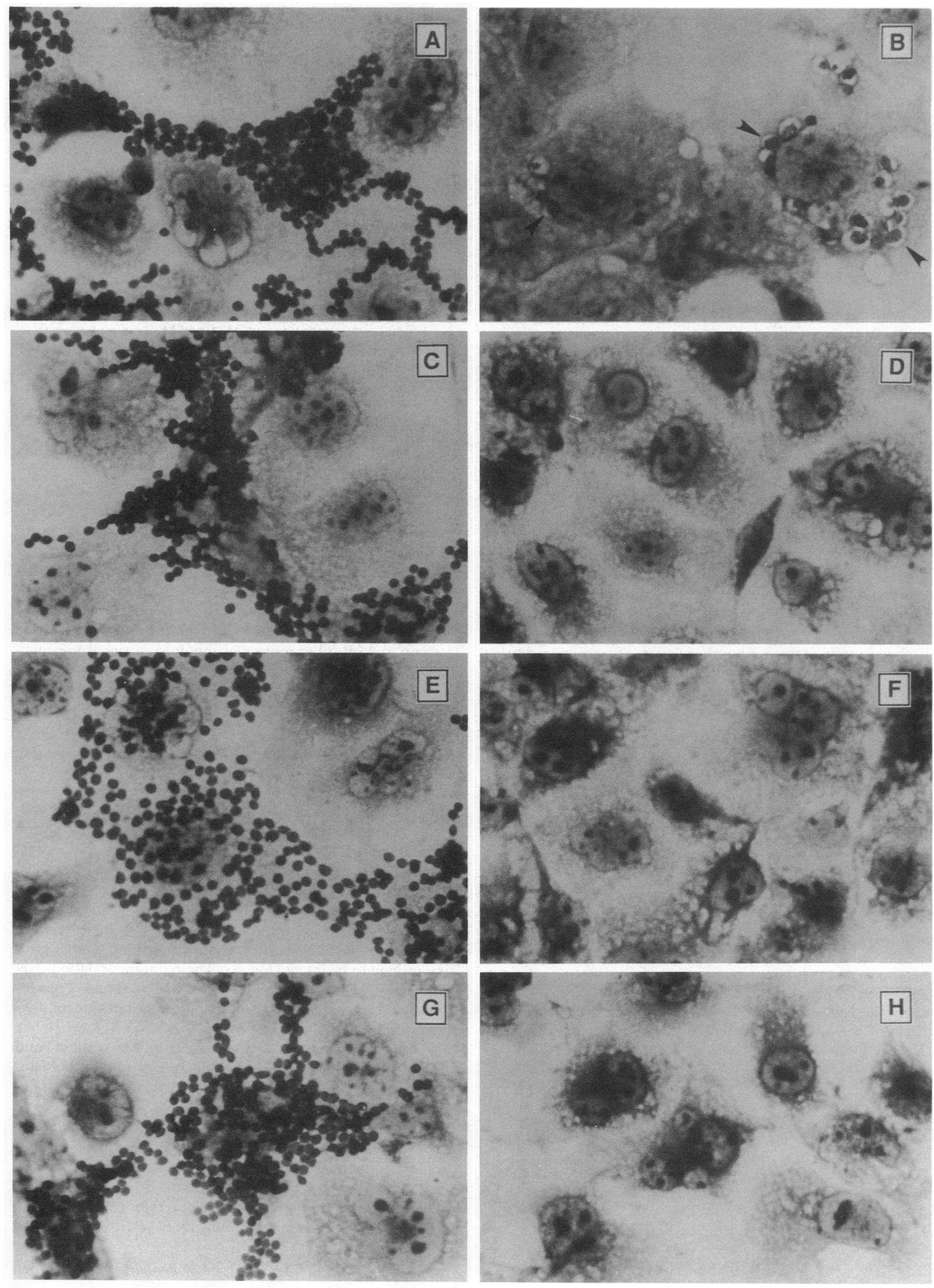
Table III. The Effect of Tyrphostin 23 (Tyr 23) on Phagocytosis by COS-1 Cells Transfected with Fc $\gamma$ RIIIA $\alpha$ and $\gamma$

\begin{tabular}{ccc}
\hline Tyr 23 & PI & Rosetting \\
\hline Concentration & & $\%$ Cells \\
$0 \mu \mathrm{M}$ & $125 \pm 24$ & $49 \pm 3$ \\
$25 \mu \mathrm{M}$ & $68 \pm 4$ & $52 \pm 9$ \\
$50 \mu \mathrm{M}$ & $26 \pm 7$ & $52 \pm 8$ \\
$100 \mu \mathrm{M}$ & $16 \pm 6$ & $49 \pm 7$ \\
$200 \mu \mathrm{M}$ & $1.2 \pm 1$ & $47 \pm 5$ \\
$400 \mu \mathrm{M}$ & 0 & $48 \pm 3$ \\
$400 \mu \mathrm{M}+$ washing & $63 \pm 7$ & $44 \pm 6$ \\
\hline
\end{tabular}

See Table I for legend.

was measured in individual transfected cells (WT, M1A, M2A, or DMA) using digital video microscopy (Fig. 4). Epinephrine, which evokes a $\mathrm{Ca}^{2+}$ signal in $\mathrm{COS}$ cells $(20)$, was used as a positive control in all experiments. Transfectants with the WT receptor complex showed a typical transient calcium rise after crosslinking. In 5 consecutive experiments ( 169 cells), $58 \%$ of cells responded to crosslinking with a calcium signal at least $50 \%$ as large as that induced by $10 \mu \mathrm{M}$ epinephrine (Fig. 4 and Table IV). In contrast, COS-1 cells transfected with either M1A, M2A, or DMA showed markedly diminished calcium responses, although in one of four experiments significant calcium mobilization was evoked in M1A-transfected COS-1 cells. Our data, therefore, demonstrate that the two cytoplasmic tyrosine residues of the $\gamma$ chain play an important role both in phagocytosis and in calcium mobilization.

\section{Discussion}

Fc $\gamma$ RIIIA is a receptor complex consisting of a single $\alpha$ chain and a homo- or heterodimer of its associated $\gamma$ and $\zeta$ chains ( 5 , 8 ). In this study, we have used cotransfection of Fc $\gamma$ RIIIA- $\alpha$ and its associated $\gamma$ (wild type or mutants) and $\zeta$ chains to examine their role in mediating phagocytosis and calcium mobilization. It should be noted that phagocytosis observed in fibroblasts after $\mathrm{Fc} \gamma$ receptor transfection has been well demonstrated by previous studies, including observations with electron microscopy by us and others $(3,14,16,23)$. The ingested EA shown in Fig. $2 B$ shows several characteristics of phagocytosis. All the ingested RBCs are enclosed in distinctive vesicles, which are demarcated by boundaries, and some RBCs show partial degradation. There also was a consistent and dramatic decrease of ingestion in the cells transfected with mutant receptors. Furthermore, cytochalasin D and cold temperature inhibited the ingestion of EA, while EA binding was unchanged.

Fc $\gamma$ RIIIA can exist in three molecular isoforms with the $\alpha$ chain associated with either $\gamma \gamma, \zeta \zeta$, or $\gamma \zeta$. The Fc $\gamma$ RIIIA- $\gamma-\gamma$ isoform is found in macrophages, while all three forms occur in NK cells that express both the $\gamma$ and $\zeta$ subunits $(24,25)$. We

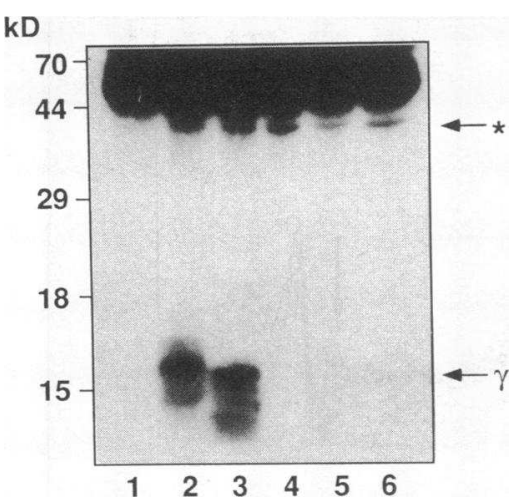

Figure 3. Tyrosine phosphorylation of the wild type and mutant $\gamma$ chains by in vitro kinase assay. The $\gamma$ chain was immunoprecipitated with anti- $\gamma$ antisera from lysates of COS-1 transfectants. In vitro phosphorylated samples were run on a $12.5 \%$ reducing SDS-

PAGE gel. The gel was treated with $1 \mathrm{~N} \mathrm{KOH}$ to remove phosphoserine and threonine, dried, and the autoradiogram was examined after 4 d. Sham, COS- 1 cells transfected with Fc $\gamma$ RIIIA- $\alpha$ cDNA and pSVL vector without $\gamma$ cDNA insert (lane 1 ). Fc $\gamma$ RIIIA $\alpha+$ wild type human $\gamma$ (lane 2). Fc $\gamma$ RIIIA $\alpha+$ wild type mouse $\gamma$ (lane 3 ). Fc $\gamma$ RIIIA $\alpha+$ M1A (lane 4). Fc $\gamma$ RIIIA $\alpha+$ M2A (lane 5). Fc $\gamma$ RIIIA $\alpha$ + DMA (lane 6). The phosphorylated $\gamma$ chains are denoted by an arrow (lower right). The arrow with an asterisk (upper right) denotes a specific tyrosine phosphoprotein band at $\sim 40 \mathrm{kD}$.

examined the phagocytic capacity of these isoforms by cotransfection of COS- 1 cells with Fc $\gamma$ RIIIA- $\gamma$ and/or $\zeta$ plus $\alpha$. The ability of both $\gamma$ and $\zeta$ to mediate a phagocytic signal may suggest redundancy in their functions. However, the higher efficiency of the $\gamma$ chain in mediating a phagocytic signal suggests important differences in the function of these two chains in vivo. For example, macrophages, which are actively phagocytic cells, express Fc $\gamma$ RIIIA in association with $\gamma$. In contrast, Fc $\gamma$ RIIIA in NK cells, which exhibit little or no phagocytic activity, may utilize $\zeta$ for such signal transduction events as ADCC.

The results obtained with the wild type and mutant $\gamma$ chains with replacement of their tyrosine residue(s) with phenylalanine demonstrate that both cytoplasmic tyrosine residues are essential for the signal transduction events involved both in phagocytosis and in intracellular free calcium mobilization. Low levels of phagocytic activity and calcium mobilization by the mutants may be explained by a small degree of undetected receptor tyrosine phosphorylation or by signal(s) independent of receptor phosphorylation. During the preparation of our manuscript, it was shown by others that the $\gamma$ subunit of Fc $\gamma$ RIIIA also plays a critical role in antigen presentation in transformed $\mathrm{B}$ cells (13) and in $\mathrm{Ca}^{2+}$ signaling in transfected T and mast cells (26). The conserved tyrosines of the $\zeta$ chain also were shown to be important for cytotoxicity and calcium mobilization in $\mathrm{T}$ cell lines (27).

Phosphorylation of receptor molecules and ensuing activation of protein tyrosine kinases are an early step in signal transduction pathways demonstrated for Fc $\gamma$ RIII/CD16 (28), FceRI, the TCR (CD3), and the B cell antigen receptors (15, $29,30)$. A conserved motif implicated in signal transduction has been described in the cytoplasmic domain of several Ig

Figure 2. Binding and phagocytosis of IgG-sensitized RBCs $(E A)$ by transfected COS-1 cells. Binding of EA by transfected COS-1 cells $(A, C, E$, and $G)$. Phagocytosis of EA by transfected COS-1 cells $(B, D, F$, and $H)$. $(A$ and $B)$ Binding and phagocytosis of COS-1 cells transfected with Fc $\gamma$ RIIIA $\alpha$ and wild type $\gamma$. Three of the phagocytosed RBCs shown with wild type $\gamma$ are marked by arrows in $B$. (C and $D)$ Transfectants containing $\alpha$ and $\gamma$ (M1A). ( $E$ and $F$ ) transfectants containing $\alpha$ and $\gamma(\mathrm{M} 2 \mathrm{~A})$. ( $G$ and $H$ ) transfectants containing $\alpha$ and $\gamma$ (DMA). No phagocytosis of EA is seen in $D, F$, and $H$. Images are shown at $\times 1,000$. 

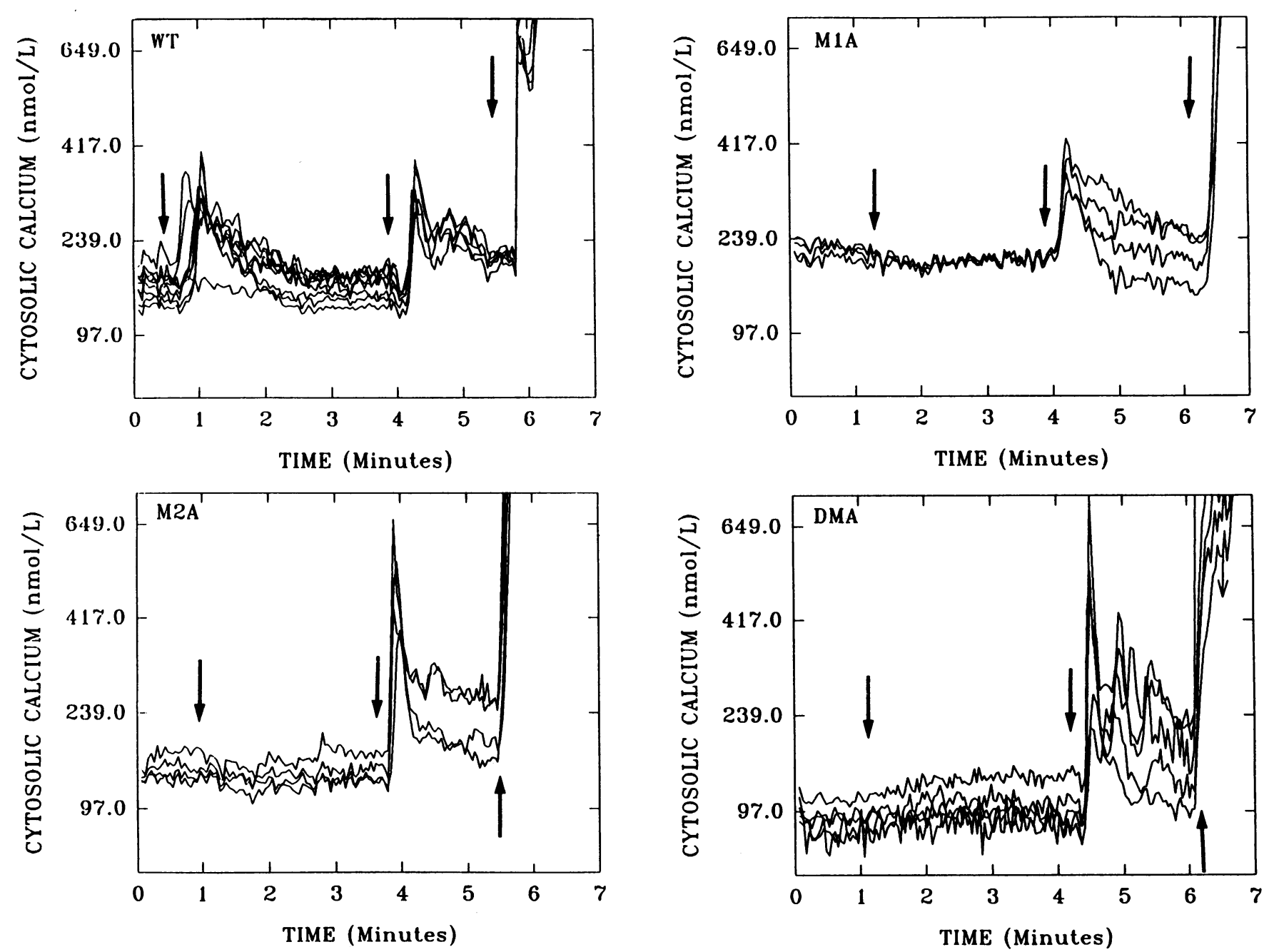

Figure 4. $\mathrm{Ca}^{2+}$ mobilization following Fc $\gamma$ RIIIA stimulation. Measurement of $\left[\mathrm{Ca}^{2+}\right] \mathrm{i}$ in individual cells was carried out during crosslinking of Fc $\gamma$ RIIIA. The time points when biotinylated anti-Fc $\gamma$ RIII + streptavidine, epinephrine (positive control), and calcium ionomycin were added are denoted by arrows from left to right, respectively, in each graph. Images were acquired at either 340- or 380-nm excitation (emission $=510$ $\mathrm{nm}) .340 / 380$ ratios were converted to $\left[\mathrm{Ca}^{2+}\right]$ i, based on calibration with Fura-2 acid (19). The responses of M1A, M2A, and DMA transfectants were greatly decreased compared to WT transfectants.

superfamily receptors (12). This motif, D/E-X2,7-D/E-X2-YX2-L-X7-Y-X2-L, which also appears in the cytoplasmic domain of the $\gamma$ and $\zeta$ chains, suggests an important role for tyrosine residues and their phosphorylation. That phagocytosis is eliminated by incubation of cells with tyr 23 , and that the wild type $\gamma$ chains but not the mutant $\gamma$ chains are phosphory-

Table IV. The Effect of Tyrosine Substitutions on Calcium

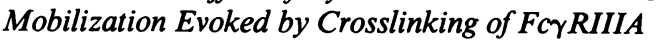

\begin{tabular}{lccc}
\hline \multicolumn{1}{c}{ Fc $\gamma$ RIII } & $\begin{array}{c}\text { No. of } \\
\text { Experiments }\end{array}$ & $\begin{array}{c}\text { No. of } \\
\text { Cells }\end{array}$ & $\begin{array}{c}\text { \% of Cells } \\
\text { Responding* }\end{array}$ \\
\hline$\alpha+\gamma$ (WT) & 5 & 169 & 57.8 \\
$\alpha+\gamma$ (M1A) & 4 & 123 & 16.0 \\
$\alpha+\gamma$ (M2A) & 4 & 117 & 2.8 \\
$\alpha+\gamma$ (DMA) & 4 & 70 & 3.7 \\
\hline
\end{tabular}

* Cells were scored as responding if the calcium response was more than $50 \%$ of that observed with $10 \mu \mathrm{M}$ epinephrine. lated in in vitro kinase assays, suggest that phosphorylation of the cytoplasmic tyrosine residues is required for phagocytic signal transduction. In vitro kinase assays using lysates of cultured monocytes also have demonstrated that the Fc $\gamma$ RIIIA $\gamma$ chain is phosphorylated on tyrosine residues (31). The cytoplasmic tyrosines of FceRI- $\gamma$ (the same $\gamma$ chain dimer complexed with a different $\alpha$ chain in mast cells) have also been shown to be reversibly phosphorylated in rat basophilic leukemia cells (15).

The nature of the phosphorylated band at $40 \mathrm{kD}$ in Fig. 3 is not known at present, but may represent a $\gamma$-associated protein tyrosine kinase. Since the phosphoprotein is coprecipitated with the mutant $\gamma$ chains as well as with the wild type $\gamma$ chain, it is unlikely that the phosphoprotein is a product of downstream events after receptor phosphorylation. It is of interest that several phosphoproteins of a similar molecular mass have been reported to associate with the cytoplasmic tails of $B$ cell receptor Ig- $\alpha$ and Ig- $\beta$ chains, which also contain a similar motif with conserved tyrosines (32).

Another $F c \gamma$ receptor, Fc $\gamma$ RIIA, which also mediates 
phagocytosis of EA, has a similarly conserved motif and is phosphorylated on tyrosine after receptor crosslinking $(3,4)$. Our data, however, suggest that there are differences in the phagocytic pathways mediated by Fc $\gamma$ RIIIA and Fc $\gamma$ RIIA. Phorbol esters decrease phagocytosis mediated by Fc $\gamma$ RIIIA (14), but increase phagocytosis by FcyRIIA in transfected COS cells (33), a hematopoietic cell line (33), and neutrophils (34). In addition, in vitro kinase data obtained from the Fc $\gamma$ RIIIA wild type and mutant $\gamma$ chains show that the phosphorylation state of the $\gamma$ chain correlates with phagocytic activity. However, the phosphorylation state of Fc $\gamma$ RIIA does not correlate directly with Fc $\gamma$ RIIA-mediated phagocytosis (Brugge, J. S., and A. D. Schreiber, manuscript submitted for publication ).

Currently we are investigating whether other cellular events such as the release of intracellular mediators and cytokines are influenced by tyrosine phosphorylation of the Fc $\gamma$ RIIIA $\gamma$ chain. These possibilities are especially attractive, considering that the TCR $\zeta$ chain is essential for antigen-stimulated signaling and is required for such diverse functions as tyrosine phosphorylation, inositol production, intracellular calcium release, and IL-2 production in T-cells (35).

\section{Acknowledgments}

The authors thank Dr. Zena K. Indik for her helpful suggestions for experiments and in preparation of the manuscript, and Dr. James Glasgow for help with use of his microscope and camera.

This research was supported in part by the National Institutes of Health under grants AI/HL-22193, HL-27068, and HL-02424.

\section{References}

1. Ravetch, J. V., and J.-P. Kinet. 1991. Fc Receptors. Annu. Rev. Immunol. 9:457-492.

2. Odin, J. A., J. C. Edberg, C. J. Painter, R. P. Kimberly, and J. C. Unkeless. 1991. Regulation of phagocytosis and $\left[\mathrm{Ca}^{2+}\right] \mathrm{i}$ flux by distinct regions of an Fc receptor. Science (Wash. DC). 254:1785-1788.

3. Indik, Z., C. Kelly, P. Chien, A. I. Levinson, and A. D. Schreiber. 1991. Human Fc $\gamma$ RII, in the absence of other Fc $\gamma$ receptors, mediates a phagocytic signal. J. Clin. Invest. 88:1766-1771.

4. Huang, M.-M., Z. Indik, L. F. Brass, J. A. Hoxie, A. D. Schreiber, and J. S. Brugge. 1992. Activation of Fc $\gamma$ RII induces tyrosine phosphorylation of multiple proteins including Fc $\gamma$ RII. J. Biol. Chem. 267:5467-5474.

5. Letourneur, O., I. C. S. Kennedy, A. T. Brini, J. R. Ortaldo, J. J. O’Shea, and J.-P. Kinet. 1991. Characterization of the family of dimers associated with Fc receptors (FceRI and FcyRIII). J. Immunology 147:2652-2656.

6. Anderson, C. L., L. Shen, D. M. Eicher, M. D. Wewers, and J. K. Gill. 1990. Phagocytosis mediated by three distinct Fc $\gamma$ receptor classes on human leukocytes. J. Exp. Med. 171:1333-1345.

7. Titus, J. A., P. Perez, A. Kaubisch, M. A. Garrido, and D. M. Segal. 1987. Human k/NK cells targeted with heterocrosslinked antibodies specifically lyse tumor cells in vitro and prevent tumor growth in vivo. J. Immunol. 139:31533158.

8. Ra, C., M.-H. E. Jouvin, U. Blank, and J.-P. Kinet. 1989. A macrophage $\mathrm{Fc} \gamma$ receptor and the mast cell receptor for IgE share an identical subunit. Nature (Lond.) 241:752-754.

9. Weissman, A. M., M. Baniyash, D. Hou, L. E. Samelson, W. H. Burgess, and R. D. Klausner. 1988. Molecular cloning of the $\zeta$ chain of the $T$ cell antigen receptor. Science (Wash. DC). 239:1018-1020.

10. Blank, U., C. Ra, L. Miller, K. White, H. Metzger, and J.-P. Kinet. 1989. Complete structure and expression in transfected cell of high affinity IgE receptor. Nature (Lond.) 337:187-189.

11. Lanier, L. L., G. Yu, and J. H. Phillips. 1991. Analysis of Fc $\gamma$ RIII (CD16) membrane expression and association with CD3 $\zeta$ and FceRI- $\gamma$ by site directed mutation. J. Immunol. 146:1571-1576.

12. Reth, M. 1989. Antigen receptor tail clue. Nature (Lond.) 338:383-384.
13. Amigorena, S., J. Salamero, J. Davoust, W. H. Fridman, and C. Bonnerrot. 1992. Tyrosine-containing motif that transduces cell activation signals also determines internalization and antigen presentation via type III receptor for IgG. Nature (Lond.) 358:337-341.

14. Park, J.-G., R. E. Isaacs, P. Chien, and A. D. Schreiber. 1993. In the absence of other receptors, Fc $\gamma$ RIIIA transmits a phagocytic signal which requires the cytoplasmic domain of its $\gamma$ subunit. J. Clin. Invest. 92:1967-1973.

15. Paolini, R., W.-H. Jouvin, and J.-P. Kinet. 1991. Phosphorylation and dephosphorylation of the high-affinity receptor for immunoglobulin $\mathrm{E}$ immediately after receptor engagement and disengagement. Nature (Lond.) 351:855858.

16. Tuijman, W. B., P. J. A. Capel, and J. G. J. van de Winkel. 1992. Human low-affinity IgG receptor Fc $\gamma$ RIIa (CD32) introduced into mouse fibroblasts mediates phagocytosis of sensitized erythrocytes. Blood. 79:1651-1656.

17. Gluzman, Y. 1981. SV40-transformed simian cells support the replication of early SV40 mutants. Cell. 23:175-182.

18. Horton, R. M., Z. Cai, S. N. Ho, and L. R. Pease. 1990. Gene splicing by overlap extension: tailor-made genes using the polymerase chain reaction. Biotechniques. 8:528-533.

19. Unkeless, J. C., E. Scigliano, and V. H. Freedman. 1988. Structure and function of human and murine receptors for IgG. Annu. Rev. Immunol. 6:251281.

20. McGillis, J. P., J. Sudduth-Klinger, G. Harrowe, M. Mitsuhashi, and D. G. Payan. 1989. Transient expression of the angiotensin II receptor: a rapid and functional analysis of a calcium-mobilizing seven-transmembrane domain receptor in COS-7 cells. Biochem. Biophysic. Res. Comm. 165:935-941.

21. Grynkiewicz, G., M. Poenie, and R. Y. Tsien. 1985. A new generation of $\mathrm{Ca}^{2+}$ indicator with greatly improved fluorescence properties. J. Biol. Chem. 260:3440-3450.

22. Yaish, P., A. Gazit, C. Gilon, and A. Levitzki. 1988. Blocking of EGF-dependent cell proliferation by EGF receptor kinase inhibitor. Science (Wash. DC). 242:933-935.

23. Kruskal, B. A., K. Sastry, A. B. Warner, C. E. Mathieu, and R. A. Ezekowitz. 1992. Phagocytic chimeric receptors require both transmembrane and cytoplasmic domains from the mannose receptor. J. Exp. Med. 176:1673-1680.

24. Ra, C., M.-H. E. Jouvin, U. Blank, and J.-P. Kinet. 1989. A macrophage $\mathrm{Fc} \gamma$ receptor and the mast cell receptor for immunoglobulin $\mathrm{E}$ share an identical subunit. Nature (Lond). 341:752-754.

25. Anderson, P., M. Caligiuri, C. O'Brian, T. Manley, J. Ritz, and S. Schlossman. 1990. Fc $\gamma$ RIII (CD16) is included in the $\zeta$ NK receptor complex expressed by human natural killer cells. Proc. Natl. Acad. Sci. USA. 87:2274-2278.

26. Wirthmueller, U., T. Kurosaki, M. S. Murakami, and J. V. Ravetch. 1992. Signal transduction by Fc $\gamma$ RIII (CD16) is mediated through the $\gamma$ chain. J. Exp. Med. 175:1381-1390.

27. Romeo, C., M. Amiot, and B. Seed. 1992. Sequence requirements for induction of cytolysis by the $\mathrm{T}$ cell antigen/Fc receptor $\zeta$ chain. Cell. 68:889-897.

28. Einspahr, K. J., R. T. Abraham, B. A. Binstadt, Y. Uehara, and P. J. Leibson. 1991. Tyrosine phosphorylation provide an early and requisite signal for the activation of natural killer cell cytotoxic function. Proc. Natl. Acad. Sci. USA. 88:6279-6283.

29. Klausner, R. D., and L. E. Samuelson. 1991. T cell antigen receptor activation pathways: the tyrosine kinase connection. Cell. 64:875-878.

30. Lane, P. J. L., J. A. Ledbetter, F. M. McConnell, K. Draves, J. Deans, G. L. Schieven, and E. A. Clark. 1991. The role of tyrosine phosphorylation in signal transduction through surface IgG in human B Cells. J. Immunol. 146:715722.

31. Darby, C., L. Lipfert, J. S. Brugge, R. L. Geahlen, and A. D. Schreiber. 1992. Macrophage Fc $\gamma$ RIIIA signaling induces protein tyrosine kinase activation. Blood. 80:352a. (Abstr.)

32. Clark, M. R., K. S. Campbell, A. Kazlauskas, S. A. Johnson, M. Hertz, T. A. Potter, C. Pleiman, and J. C. Cambier. 1992. The B cell antigen receptor complex; association of Ig- $\alpha$ and $\mathrm{Ig}-\beta$ with distinct cytoplasmic effectors. Science (Wash. DC). 258:123-126.

33. Kelly, C. J., Z. K. Indik, R. Isaacs, P. Chien, J. M. Daly, and A. D. Schreiber. 1991. The human platelet/megakaryocyte Fc $\gamma$ receptor (Fc $\gamma$ RII) mediates a phagocytic signal which is enhanced by phorbol ester activation. Blood. 78:393a. (Abstr.)

34. Rosales, C., and E. J. Brown. 1991. Two mechanisms for IgG Fc receptormediated phagocytosis by human neutrophils. J. Immunol. 146:3937-3944.

35. Irving, B. A., and A. Weiss. 1991. The cytoplasmic domain of the T cell receptor $\zeta$ chain is sufficient to couple to receptor-associated signal transduction pathway. Cell. 64:891-901.

36. Ra, C., M.-H. E. Jouvin, and J.-P. Kinet. 1989. Complete structure of the mouse mast cell receptor for IgE (FceRI) and surface expression of chimeric receptors (rat-mouse-human) on transfected cells. J. Biol. Chem. 264:1532315327. 